\title{
Bioluminescent monitoring of detoxification processes
}

Rozhko T.V. ${ }^{1}$, Kudryasheva N.S. ${ }^{2,3}$

${ }^{1}$ Krasnoyarsk Medical Academy, Krasnoyarsk, Russia, gutniktv72@mail.ru

${ }^{2}$ Institute of Biophysics FRC KSC SB RAS, Krasnoyarsk, Russia

${ }^{3}$ Siberian Federal University, Krasnoyarsk, Russia

Keywords: detoxification, enzymatic bioassay, bioluminescence, humic substances

doi: 10.36291/HIT.2019.rozhko.076

Bioluminescence of marine bacteria is sensitive to toxic compounds. That is why the bacterial bioluminescent assay systems are used as biosensors in ecology and medicine.

Bioluminescent assays in vivo and in vitro were used to monitor detoxification of solutions of radionuclides of low activity by humic substances (HS).

Effects of low-level radiation on bioluminescent assay systems in vivo and in vitro were studied. Bioluminescent assay systems of different levels of organization were used: intact bacteria and bioluminescent enzyme reactions. Solutions of $241 \mathrm{Am}$ and Tritiated water (HTO) were used as sources of radiation.

Detoxification of the radioactive solutions by HS was under study. It was shown that HS change bioluminescence kinetics in 241Am solutions approaching it to control.

HTO and HS demonstrated synergetic activation effect on the bioluminescence enzymatic bioassay.

Acknowledgements. The work was supported by the PRAN-32, grant of RFBR N1829-19003, RFBR and Krasnoyarsk Regional Foundation N18-44-242002, N18-44-240004. 